\title{
SEPARATION OF TANTALUM AND NIOBIUM FROM THE TREATED SULFATE LIQUOR USING ISODECANOL
}

\author{
Saleh M. EI Hady \\ Nuclear Materials Authority, P.O. Box: 530 El Maadi, Cairo, Egypt
}

\begin{abstract}
A technological sample of polymetallic sedimentary rocks collected from southwestern Sinai $\left(2.61 \% \quad \mathrm{RE}_{2} \mathrm{O}_{3}, 1.14 \% \quad \mathrm{Ta}_{2} \mathrm{O}_{5}\right.$ and $\left.2.16 \% \quad \mathrm{Nb}_{2} \mathrm{O}_{5}\right)$ is subjected to processing via sulfuric acid agitation leaching under different conditions. The produced sulfate liquor is chemically treated involving precipitation of REEs as oxalates. The treated sulfate solution was obtained and used for recovery of $\mathrm{Nb}$ and $\mathrm{Ta}$ using solvent extraction as isodecanol. The relevant factors for the extraction and stripping processes of $\mathrm{Nb}$ and $\mathrm{Ta}$ have been optimized. Highly pure products of $\mathrm{Nb}$ and $\mathrm{Ta}$ have properly been prepared and analyzed using ICP-MS.
\end{abstract}

Keywords: Niobium; Tantalum; Sulfate liquor; Isodecanol; Solvent extraction.

\section{Introduction}

The application of niobium and tantalum over the past two decades is increasing as a result of their importance in the production of modern industrial materials, high tech consumer products and strategic energy technologies such as super alloys, electronic devices, solar, wind and nuclear equipment, in conjunction with other elements such as tellurium, indium, silver, dysprosium, neodymium and molybdenum (He et al., 1998) (Hayes and Burge, 2003) (Cunningham, 2000) (Moss et al., 2011) (Lowder, 2012) (Pell and Hora, 1990). $\mathrm{Nb}$ and Ta are presented from a variety of minerals and concentrates. The major source of these two metals is the columbitetantalite mineral, also called coltan, $(\mathrm{Fe}, \mathrm{Mn})(\mathrm{Nb}, \mathrm{Ta})_{2} \mathrm{O}_{6}$ which contains $(5-$ $30 \% \mathrm{Ta}_{2} \mathrm{O}_{5}$ in columbite and $42-84 \% \mathrm{Ta}_{2} \mathrm{O}_{5}$ in tantalite) and $(55-78 \%$ $\mathrm{Nb}_{2} \mathrm{O}_{5}$ in columbite and $2-40 \% \mathrm{Nb}_{2} \mathrm{O}_{5}$ in tantalite). Ta and $\mathrm{Nb}$ exist in other minerals (more than 150) as complex oxides and hydroxides with the exception of the borate mineral behierite $(\mathrm{Ta}, \mathrm{Nb})\left(\mathrm{BO}_{4}\right)$ and the only known non-oxide mineral containing tantalum carbide $\mathrm{TaC}$ (Nete et al., 2016). These two metals $(\mathrm{Nb} \& \mathrm{Ta})$ are presented in the present study for the polymetallic sedimentary rocks of Um Tomyem area, southwestern Sinai. 
Extraction of tantalum and niobium from their ores has several studies which investigated the development of the successful dissolution of $\mathrm{Ta} / \mathrm{Nb}$ sources followed by their separation and purification. The former included fusion digestion using different fluxes such as $\mathrm{KHSO}_{4}, \mathrm{Na}_{2} \mathrm{~S}_{2} \mathrm{O}_{7}, \mathrm{KHF}_{2}, \mathrm{Na}_{2} \mathrm{CO}_{3}$, borax and alkali hydroxides (El-Hazek et al., 2009) (Borchers and Korinek, 1981) (Gupta and Suri, 1994) (Eckert, 1995) (Wang et al., 2009) (El Hussaini and Mahdy, 1998) (Zhou et al., 2005) as well as acid leaching techniques such as $\mathrm{H}_{2} \mathrm{SO}_{4}, \mathrm{HNO}_{3}, \mathrm{HF}$ and $\mathrm{HCl}$ (Ayanda and Adekola, 2011) (El Hussaini and Mahdy, 2002) (Htwe and Lwin, 2008) (Irfan and Ahmad, 2014) (Compderros and Marchese, 2001). The latter included several procedures namely, precipitation, distillation, solvent extraction and ion exchange resin technique. Solvent extraction can be considered the most common separation method and has a number of important advantages such as the reduction of the number of production steps and cleaner tantalum and niobium products. Several extraction systems have been studied and some of them have proved to be highly successful to the extent that they have already been adopted for industrial productions. The studied exctractants include MIBK, TBP, cyclohexanone, DEHPA, DIPK, Alamine 336 and octanol (Compderros and Marchese, 2001) (IAEA, 2003) (Ritcey and Ashbrook, 1979) (Zhu and Cheng, 2011) (El Hussaini, 2009) (El-Hazek et al., 2012) (Agulyansky et al., 2004) (Mayorov and Nikolaev, 2002) (Maiorov et al., 2001) (El Hussaini and Mahdy, 2001) (El Hussaini and Rice, 2004).

The present work is concerned with the chemical processing of polymetallic sedimentary rocks collected from Um Tomyem area, southwestern Sinai for the recovery of $\mathrm{Nb}$ and $\mathrm{Ta}$ metal values. For this purpose, the working ore sample is subjected to complete chemical analysis and processing via sulfuric acid agitation leaching. The relevant factors of the acid leaching step have first been studied and after water washing of the residue, both the REEs, $\mathrm{Nb}$ and Ta values have been dissolved. From the latter, the REEs have been precipitated as their oxalates while recovery of the $\mathrm{Ta}$ and $\mathrm{Nb}$ value left behind has properly been studied via solvent extraction technique using isodecanol.

\section{Experimental}

\section{Material characterization}

The collected technological sample representing the polymetallic sedimentary rocks of Um Tomyem area, southwestern Sinai has first been subjected to complete chemical analysis of the major oxides as well as for some interesting metal values. The major oxides were analyzed using the conventional wet procedure of Shapiro and Brannock (1962). For Ca and Mg, a titrimetic method with EDTA and Eriochrome black T as indicator was 
used. The spectrometric analysis was used for $\mathrm{SiO}_{2}, \mathrm{Al}_{2} \mathrm{O}_{3}, \mathrm{P}_{2} \mathrm{O}_{5}$ and $\mathrm{Fe}_{2} \mathrm{O}_{3}$ (total) while for $\mathrm{Na}_{2} \mathrm{O}$ and $\mathrm{K}_{2} \mathrm{O}$, flame photometry was used. Weighed sample portions were used to estimate the loss of ignition at various temperature degrees. The total loss of ignition (obtained at $1000{ }^{\circ} \mathrm{C}$ ) is corresponding to humidity, combined water, $\mathrm{CO}_{2}$ as well as possible organic matter.

On the other hand, analysis of the interesting metal values; viz the REEs (in terms of La) has spectrophotometrically been determined using Arsenazo-III as the chromogenic reagent (Merczenko and Balcerzek, 2000) while Nb, Ta and Ti were determined by ICP-MS Egilant technologist 7700 serial, Japan in the labs of the Chemical Warefare.

\section{Experimental Procedures Sulfuric acid leaching}

Each leaching experiment has been performed by agitation a weighed amount of the working Um Tomyem ore material $(10 \mathrm{~g})$ with $\mathrm{H}_{2} \mathrm{SO}_{4}$ acid of different concentrations with different solid/liquid ratios for different periods of time at different temperatures. In these experiments, a hot plate with magnetic stirrer was used and precautions were taken for avoid evaporation. The obtained slurry was then cooled, filtered, washed with distilled water and made up to volume for REEs, $\mathrm{Nb}$ and $\mathrm{Ta}$ analysis.

\section{Solvent extraction of $\mathbf{N b}$ and $\mathrm{Ta}$}

To study the recovery of both $\mathrm{Nb}$ and $\mathrm{Ta}$, a $500 \mathrm{~g}$ sample portion of the working Um Tomyem ore material was subjected to sulfuric acid agitation leaching under the optimum conditions of acid leaching followed by cooling and proper washing of the slurry. From the obtained sulfate leach liquor, the REEs were relatively recovered by their direct precipitation as oxalates while $\mathrm{Nb}$ and $\mathrm{Ta}$ were left behind in the solution.

$\mathrm{Nb}$ and $\mathrm{Ta}$ were extracted from the treated sulfate liquor (free of REEs) using the organic solvent isodecanol. The solvent was diluted in kerosene to prepare different concentrations. In each extraction experiment, the organic phase was conducted with the aqueous phase in separating funnel where they shaked together for the desired time. The two phases were then allowed to settle, separate and an aliquot sample of the aqueous phase was analyzed for its remaining metal content in order to calculate the extraction efficiency.

The relevant solvent extraction factors; namely solvent concentration, the contact time and the $\mathrm{pH}$ of the leach liquor as well as aqueous/ organic ratio (A/O) were studied. On the other hand, a loaded solvent sample was prepared for studying the stripping behavior of the extracted metal value using the same procedures as that used for extraction. 


\section{Control analysis}

For the control analysis of all the performed experiments, REEs, $\mathrm{Nb}$ and $\mathrm{Ta}$ have been analyzed in all the working stream solutions via the above mentioned procedures; viz spectrophotometric and ICP-MS respectively. On the other hand, the two highly pure products of both $\mathrm{Nb}$ and Ta were analyzed in the labs of the Chemical Warefare using ICP-MS.

\section{Results and discussion}

Material characteristics

Chemical composition of Um Tomyem ore material shown in Table (1) indicated that the ore material is mainly composed of $\mathrm{SiO}_{2}$ beside $\mathrm{Al}_{2} \mathrm{O}_{3}$ and $\mathrm{Fe}_{2} \mathrm{O}_{3}$ that attained $3.5 \%$ and $8.8 \%$ respectively, as well as high $\mathrm{K}_{2} \mathrm{O}$ content (3.9\%). In the meantime, a total loss of ignition of about 0.86 was obtained at $1000{ }^{\circ} \mathrm{C}$. On the other hand, analysis of the economic trace metals involved $\mathrm{RE}_{2} \mathrm{O}_{3} 2.61 \%, \mathrm{Nb}_{2} \mathrm{O}_{5} 2.16 \%$ beside $\mathrm{Ta}_{2} \mathrm{O}_{5} 1.14 \%$.

Table 1. Chemical composition of Um Tomyem ore material.

\begin{tabular}{cccc}
\hline Major constituent & Wt., \% & trace constituent & Wt., \% \\
\hline $\mathrm{SiO}_{2}$ & 70.29 & $\mathrm{RE}_{2} \mathrm{O}_{3}{ }^{*}$ & 2.61 \\
$\mathrm{TiO}_{2}$ & 2.15 & $\mathrm{Nb}_{2} \mathrm{O}_{5}$ & 2.16 \\
$\mathrm{Al}_{2} \mathrm{O}_{3}$ & 3.50 & $\mathrm{Ta}_{2} \mathrm{O}_{5}$ & 1.14 \\
$\mathrm{Fe}_{2} \mathrm{O}_{3}$ & 8.80 & $\mathrm{U}_{3} \mathrm{O}_{8}$ & 0.02 \\
$\mathrm{CaO}$ & 1.44 & $\mathrm{ThO}_{2}$ & 0.04 \\
$\mathrm{MgO}$ & 0.90 & $\mathrm{~V}_{2} \mathrm{O}_{5}$ & 0.01 \\
$\mathrm{MnO}$ & 0.04 & $\mathrm{BeO}$ & 0.02 \\
$\mathrm{Na}$ & 2.03 & & \\
$\mathrm{~K}_{2} \mathrm{O}$ & 3.90 & & \\
$\mathrm{P}_{2} \mathrm{O}_{5}$ & 0.08 & & \\
$\mathrm{~L} . \mathrm{O} . \mathrm{I}$ & 0.86 & & \\
$\mathrm{~T} . \mathrm{H}$ & & &
\end{tabular}

Total

99.99

* $\mathrm{RE}_{2} \mathrm{O}_{3}$ measured as light rare earths (lanthanum).

\section{Leaching studies}

\section{Acid agitation leaching of $\mathrm{Nb}$, Ta and REEs}

\section{Effect of $\mathrm{H}_{2} \mathrm{SO}_{4}$ acid concentration}

To study the effect of $\mathrm{H}_{2} \mathrm{SO}_{4}$ conc. upon leaching efficiency of the studied ore material, a set of leaching experiments was performed using different concentrations of the $\mathrm{H}_{2} \mathrm{SO}_{4}$ acid ranging from 100 to $400 \mathrm{~g} / \mathrm{l}$. The other leaching conditions were fixed at $100{ }^{\circ} \mathrm{C}$ for $1 \mathrm{~h}$ and $\mathrm{S} / \mathrm{L}$ ratio of $1 / 1$. From the obtained data in Table (2), it is clear that the leaching efficiencies of REEs, $\mathrm{Nb}$ and $\mathrm{Ta}$ increased from 22.7 to $36.8 \%$, from 12.2 to $23.4 \%$ and 
from 13.9 to $25.8 \%$ respectively by increasing the acid concentration from 100 to $300 \mathrm{~g} / \mathrm{l}$. Further, increase in $\mathrm{H}_{2} \mathrm{SO}_{4}$ conc. at $400 \mathrm{~g} / \mathrm{l}$ has not improved the leaching efficiencies of REEs, $\mathrm{Nb}$ and Ta. From hence, the best acid concentration for leaching metal values is $300 \mathrm{~g} / \mathrm{l}$. The dissolution of $\mathrm{Nb}$ and $\mathrm{Ta}$ is low due to that elements are refractory (strong crystal lattice).

Table 2. Effect of $\mathrm{H}_{2} \mathrm{SO}_{4}$ conc. upon leaching efficiency of the studied metal values of Um Tomyem ore material.

\begin{tabular}{cccc}
\hline Conc. $\mathbf{H}_{2} \mathbf{S O}_{4}$, & \multicolumn{3}{c}{ Leaching efficiency, \% } \\
\cline { 2 - 4 }$(\mathbf{g} / \mathbf{l})$ & REEs & $\mathbf{~ N b}$ & Ta \\
\hline 100 & 22.7 & 12.2 & 13.9 \\
200 & 28.9 & 18.9 & 17.9 \\
300 & 36.8 & 23.4 & 25.8 \\
400 & 39.7 & 23.8 & 26.1 \\
\hline
\end{tabular}

\section{Effect of Solid/Liquid ratio (S/L)}

The effect of $\mathrm{S} / \mathrm{L}$ ratio upon the leaching of the interesting metal values of the ore material under consideration was studied from the ratio $1 / 1$ to the ratio $1 / 2.5$ when applying $\mathrm{H}_{2} \mathrm{SO}_{4}$ conc. of $300 \mathrm{~g} / 1,100{ }^{\circ} \mathrm{C}$ as leaching temperature and $1 \mathrm{~h}$ as leaching time. From the obtained data in Table (3), it is clear that the leaching efficiencies of REE, $\mathrm{Nb}$ and $\mathrm{Ta}$ increased from 44.7 to $56.8 \%$, from 23.8 to $33.4 \%$ and from 26.1 to $32.8 \%$ respectively by increasing the $\mathrm{S} / \mathrm{L}$ ratio from $1 / 1$ to $1 / 2$. Further, increase in the $\mathrm{S} / \mathrm{L}$ ratio at $1 / 2.5$ has not improved the leaching efficiencies of REEs, $\mathrm{Nb}$ and Ta. From hence, the best $\mathrm{S} / \mathrm{L}$ ratio for leaching metal values is $1 / 2$. It is obvious that $300 \mathrm{~g} / \mathrm{l} \mathrm{H}_{2} \mathrm{SO}_{4}$ cannot enough breakdown the $\mathrm{Nb}$-Ta mineral lattice even at $1 / 2.5 \mathrm{~S} / \mathrm{L}$ ratio.

Table 3. Effect of S/L ratio upon leaching efficiency of the studied metal values of Um Tomyem ore material.

\begin{tabular}{cccc}
\hline S/L & \multicolumn{3}{c}{ Leaching efficiency, \% } \\
\cline { 2 - 4 } ratio & REEs & $\mathbf{N b}$ & Ta \\
\hline $1 / 1$ & 44.7 & 23.8 & 26.1 \\
$1 / 1.5$ & 48.9 & 28.9 & 28.7 \\
$1 / 2$ & 56.8 & 33.4 & 32.8 \\
$1 / 2.5$ & 57.7 & 33.9 & 33.1 \\
\hline
\end{tabular}

\section{Effect of agitation time}

To study the effect of agitation time upon the leaching efficiency of the interested metals, a set of leaching experiments has been performed at different times ranging from 1 to $4 \mathrm{~h}$. The other leaching conditions were fixed at $\mathrm{H}_{2} \mathrm{SO}_{4}$ conc. of $300 \mathrm{~g} / \mathrm{l}, 1 / 2 \mathrm{~S} / \mathrm{L}$ ratio at $100{ }^{\circ} \mathrm{C}$. From the obtained 
results in Table (4), it is obvious that the refractory nature of the study ore material required long leaching periods of time under the applied leaching conditions, where the leaching efficiencies of REEs, $\mathrm{Nb}$ and Ta increased from 56.8 to $61.3 \%$, from 33.4 to $49.9 \%$ and from 32.8 to $45.8 \%$ respectively by increasing the time from 1 to $3 \mathrm{~h}$. Further, increase in the time at $4 \mathrm{~h}$ has not improved the leaching efficiencies of REEs, $\mathrm{Nb}$ and Ta. So, the leaching time of $3 \mathrm{~h}$ is the optimum time for leaching of interesting metal values.

Table 4. Effect of agitation time upon leaching efficiency of the studied metal values of Um Tomyem ore material.

\begin{tabular}{cccc}
\hline Time, $\mathbf{h}$. & \multicolumn{3}{c}{ Leaching efficiency, \% } \\
\cline { 2 - 4 } & REEs & Nb & Ta \\
\hline 1 & 56.8 & 33.4 & 32.8 \\
2 & 57.6 & 38.8 & 39.9 \\
3 & 61.3 & 49.9 & 45.8 \\
4 & 61.8 & 50.2 & 46.2 \\
\hline
\end{tabular}

\subsubsection{Effect of leaching temperature}

The effect of leaching temperature upon the leaching efficiencies of the interested metal values was investigated in the range from 100 up to $300{ }^{\circ} \mathrm{C}$ under the fixed experimental conditions of $300 \mathrm{~g} / \mathrm{H} \mathrm{H}_{2} \mathrm{SO}_{4}$ conc., $\mathrm{S} / \mathrm{L}$ ratio of $1 / 2$ and leaching time of $3 \mathrm{~h}$. From the obtained data in Table (5), it is clear that the refractory nature of the polymetallic ore material has required high temp. up to $300{ }^{\circ} \mathrm{C}$ to be broken, where the REEs, $\mathrm{Nb}$ and Ta leaching efficiencies increased from 61.3 to $99.9 \%$, from 49.9 to $98.2 \%$ and from 45.8 to $99.2 \%$ respectively with increasing the temperature from 100 to $300{ }^{\circ} \mathrm{C}$ under the applied leaching conditions. So, the leaching temperature of $300{ }^{\circ} \mathrm{C}$ is the optimum temperature for leaching of interesting metal values.

Table 5. Effect of leaching temperature upon leaching efficiency of the studied metal values of Um Tomyem ore material.

\begin{tabular}{cccc}
\hline Temp., ${ }^{\mathbf{}} \mathbf{C}$. & \multicolumn{3}{c}{ Leaching efficiency, \% } \\
\cline { 2 - 4 } & REEs & Nb & Ta \\
\hline 100 & 61.3 & 49.9 & 45.8 \\
150 & 74.5 & 59.8 & 61.2 \\
200 & 88.6 & 73.5 & 77.7 \\
250 & 91.2 & 88.4 & 90.2 \\
300 & 99.9 & 98.2 & 99.2 \\
\hline
\end{tabular}


From the above studied acid agitation leaching factors of Um Tomyem ore material, it can be concluded that the optimum conditions for almost complete dissolution the interesting metal values can be summarized as follows:

$\mathrm{H}_{2} \mathrm{SO}_{4}$ acid concentration $\quad: 300 \mathrm{~g} / \mathrm{l}$

S/L ratio

Leaching time : $3 \mathrm{~h}$.

Leaching temperature $\quad: \quad 300{ }^{\circ} \mathrm{C}$

\section{Preparation of the sulfate leach liquor}

The sulfate solution of polymetallic ore sample of Um Tomyem area, southwestern Sinai was prepared by applying the above optimum factors followed by filtration and washing the residue with distillated water to attain up to volume $2 \mathrm{~L}$. Analysis of the latter is shown in Table (6). From the latter, the produced pregnant solution $\mathrm{pH}$ is 1.8 and assays $8.5 \mathrm{~g} / \mathrm{l}$ REEs, $5.32 \mathrm{~g} / \mathrm{l} \mathrm{Nb}$ and $2.74 \mathrm{~g} / \mathrm{l} \mathrm{Ta}$ with almost complete dissolution of $\mathrm{Nb}$, Ta and REEs.

Table 6. Chemical composition of the prepared sulfate solution.

\begin{tabular}{cc}
\hline Constituent & Concentration, g/l \\
\hline $\mathrm{Fe}_{2} \mathrm{O}_{3}$ & 6.24 \\
$\mathrm{Al}_{2} \mathrm{O}_{3}$ & 3.34 \\
$\mathrm{RE}_{2} \mathrm{O}_{3} *$ & 8.50 \\
$\mathrm{Nb}_{2} \mathrm{O}_{5}$ & 5.32 \\
$\mathrm{Ta}_{2} \mathrm{O}_{5}$ & 2.74 \\
$\mathrm{pH}$ & 1.8 \\
\hline
\end{tabular}

\section{Treatment of the sulfate leach liquor of the polymetallic ore sample}

The prepared sulfate leach liquor is used to extract the interesting metal values $\mathrm{Nb}$, Ta and REE. Thus, REE is recovered using direct precipitation technique. The latter carried out using $10 \%$ oxalic acid. At $\mathrm{pH} 0.8$, almost complete REEs precipitation occurred where their precipitation efficiencies attained $97.4 \%$. The REEs product can be calcined at $800{ }^{\circ} \mathrm{C}$ and analyzed using UV-Visible spectrophotometer which indicated a REE purity of $94.7 \%$. The produced solution free of REEs presented the treated sulfate liquor for separation of $\mathrm{Nb}$ and $\mathrm{Ta}$.

\section{Recovery of tantalum and niobium}

Solvent isodecanol $\left(\mathrm{C}_{10} \mathrm{H}_{22} \mathrm{O}\right)$ was chosen for extracting both $\mathrm{Nb}$ and Ta from the treated sulfate solution because of its availability and low cost. Generally, the good solvating character of isodecanol may be due to its high dipole moment and the presence of electronegative $\mathrm{O}-\mathrm{H}$ bond. The molecular formula of isodecanol is $\left\{\mathrm{CH}_{3}\left(\mathrm{CH}_{3}\right) \mathrm{CH}\left(\mathrm{CH}_{2}\right)_{6} \mathrm{CH}_{3}(\mathrm{OH})\right\}$ and density = 0.841. Alcohols of $\mathrm{C}_{8}-\mathrm{C}_{12}$ chain length could have particular interest as prospective extractants for LLE (Liquid-Liquid extraction) where 1-octanol provides efficiency comparable with both MIBK and TBP in LLE of tantalum 
and niobium. Isodecanol main advantages are insoluble in water, sufficiently less volatile and less dangerous.

\section{antalum and niobium extraction}

In practice, the principal solvent extraction factors including solvent concentration in the organic phase, the optimum contact time, the $\mathrm{pH}$ of the leach liquor and the aqueous / organic ratio $(\mathrm{A} / \mathrm{O})$ were studied for each of the two interesting metal values namely; $\mathrm{Nb}$ and $\mathrm{Ta}$.

\section{Effect of isodecanol concentration}

This effect was studied upon the $\mathrm{Ta}$ and $\mathrm{Nb}$ extraction efficiencies by contacting equal volumes of the treated sulfate solution with solvent of different concentrations ranging from 25 to $100 \%$ at the fixed conditions of pH 0.9, contact time of $12 \mathrm{~min}$. From the obtained data in Table (7), it is noticed that extraction efficiency of $\mathrm{Ta}$ and $\mathrm{Nb}$ increased from 24.1 to $99.7 \%$ and from 19.2 to $99.3 \%$ when isodecanol concentration increased from 25 to $100 \%$, respectively.

Table 7. Effect of isodecanol concentration upon extraction efficiency of Ta and $\mathrm{Nb}$.

\begin{tabular}{ccc}
\hline Solvent Concentration, $\%$ & \multicolumn{2}{c}{ Extraction efficiency, $\%$} \\
\cline { 2 - 3 } & $\mathbf{T a}$ & $\mathbf{N b}$ \\
\hline 25 & 24.1 & 19.2 \\
50 & 46.3 & 56.7 \\
75 & 76.6 & 80.1 \\
100 & 99.7 & 99.3 \\
\hline
\end{tabular}

\section{Effect of $\mathrm{pH}$ of the treated sulfate liquor}

To study the effect of $\mathrm{pH}$ of the treated sulfate solution upon $\mathrm{Ta}$ and $\mathrm{Nb}$ extraction efficiencies, a set of experiments was performed at different $\mathrm{pH}$ values of the treated sulfate liquor ranging from $\mathrm{pH} 2.1$ to 0.9 at the fixed conditions of A/O 1:1, $100 \%$ isodecanol \& $12 \mathrm{~min}$ as contact time. From the shown results (Table 8), it is clear that extraction efficiency of $\mathrm{Ta}$ and $\mathrm{Nb}$ increased from 53.6 to $99.7 \%$ and from 00.0 to $99.3 \%$ when $\mathrm{pH}$ of the treated sulfate liquor decreased from 2.1 to 0.9 , respectively.

Table 8. Effect of $\mathrm{pH}$ upon the extraction efficiency of Ta and $\mathrm{Nb}$.

\begin{tabular}{ccc}
\hline $\mathbf{p H}$ & \multicolumn{2}{c}{ Extraction efficiency, \% } \\
\cline { 2 - 3 } & $\mathbf{T a}$ & $\mathbf{N b}$ \\
\hline 2.1 & 53.6 & nil \\
1.8 & 98.4 & 19.2 \\
1.5 & 99.1 & 45.2 \\
1.2 & 99.4 & 74.3 \\
0.9 & 99.7 & 99.3 \\
\hline
\end{tabular}




\section{Effect of contact time}

To study the effect of contact time upon the extraction efficiency of Ta and $\mathrm{Nb}$ using isodecanol, a set of experiments has been performed at different contact times ranging from 4 to $12 \mathrm{~min}$ at the fixed conditions of $\mathrm{A} / \mathrm{O}$ ratio $1: 1,100 \%$ isodecanol concentration $\& \mathrm{pH}$ value 0.9 . The results are shown in Table (9). From the latter, it is obvious that increasing the contact time between the leach liquor and the organic phase from 4 to $12 \mathrm{~min}$, increase Ta and $\mathrm{Nb}$ extraction efficiencies from 27.5 to $99.7 \%$ and from 13.6 to $99.3 \%$, respectively.

Table 9. Effect of contact time upon the extraction efficiency of $\mathrm{Ta}$ and $\mathrm{Nb}$.

\begin{tabular}{ccc}
\hline Time, $\boldsymbol{m i n}$ & \multicolumn{2}{c}{ Extraction efficiency, $\mathbf{\%}$} \\
\cline { 2 - 3 } & $\mathbf{T a}$ & $\mathbf{N b}$ \\
\hline 4 & 27.5 & 13.6 \\
6 & 57.8 & 55.5 \\
8 & 80.1 & 77.2 \\
10 & 95.2 & 89.1 \\
12 & 99.7 & 99.3 \\
\hline
\end{tabular}

\section{Construction of McCabe-Thiele diagram for Ta \& Nb extraction}

From the treated sulfate liquor, the effect of the aqueous / organic (v/v) phase ratio upon the extraction of $\mathrm{Ta}$ and $\mathrm{Nb}$ were investigated in the range of 3:1 down to $1: 3$ while fixing the other extraction factors at their determined optimum values (100\% isodecanol, $12 \mathrm{~min}$ as contact time at room temperature and the $\mathrm{pH}$ value of the aqueous phase of 0.9$)$. On the other hand, McCabe-Thiele diagram is constructed from the obtained equilibrium data of $\mathrm{Ta}$ and $\mathrm{Nb}$ extraction as shown in Fig. 1 \& 2. From this diagram, the required theoretical number of extraction stages would be determined. According to the slope of the chosen operating line which was found to attain $3(\mathrm{~A} / \mathrm{O}), 3$ theoretical stages would be required for almost complete extraction of $\mathrm{Ta}$ and $\mathrm{Nb}$ from the treated sulfate leach liquor (free of REEs).

\section{Tantalum and niobium stripping}

Tantalum and niobium stripping were carried out by shaking equal volumes of the loaded solvent with a suitable stripping solution for a certain time at room temperature. Factors influencing the stripping efficiency were studied. These include stripping agent type, concentration, stripping time and aqueous to organic phase ratio $(\mathrm{A} / \mathrm{O})$. The concentration of $\mathrm{Ta}$ and $\mathrm{Nb}$ in the loaded solvent was 2709 and 5310 ppm, respectively. 


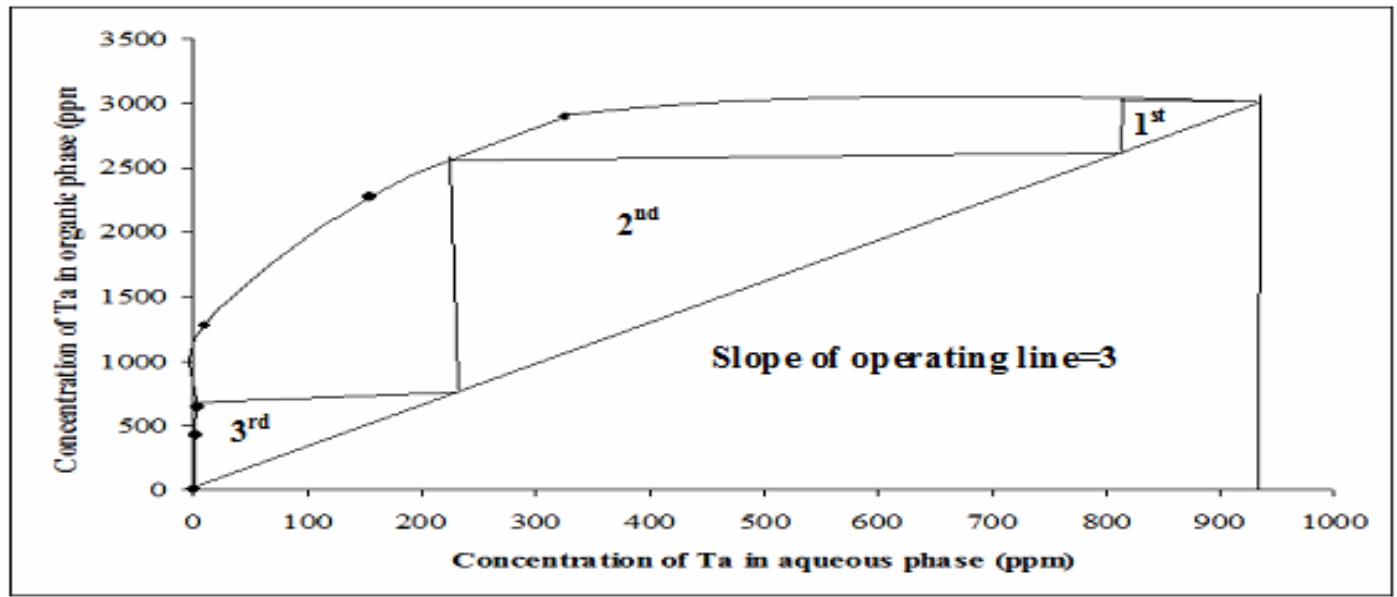

Fig. 1. McCabe-Thiele diagram for Ta extraction.

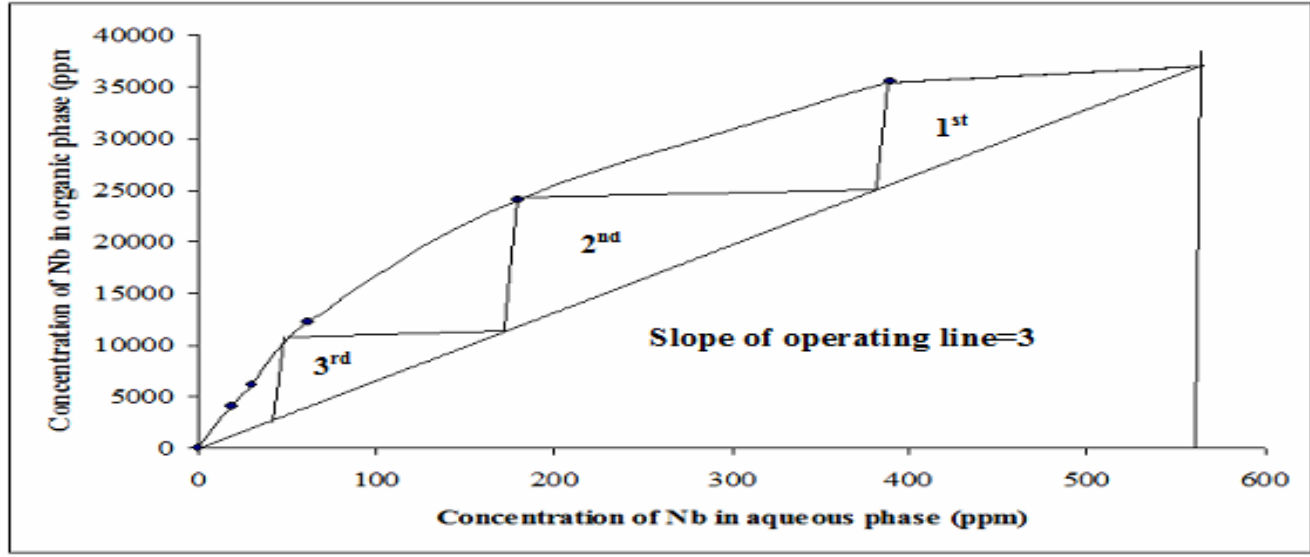

Fig. 2. McCabe-Thiele diagram for $\mathrm{Nb}$ extraction.

To strip $\mathrm{Ta}$ and $\mathrm{Nb}$ from the loaded solvent, different stripping agents were studied. These included distilled water, mineral acids namely; $\mathrm{H}_{2} \mathrm{SO}_{4}, \mathrm{HF}$ and $\mathrm{HNO}_{3}(0.3 \mathrm{M})$. The stripping experiments were conducted at 3 min contact time and 1/1 A/O ratio as shown in Table (10). The obtained results revealed that distilled water is the most efficient for stripping Ta from the loaded solvent while $\mathrm{Nb}$ remains in the organic phase. On the other hand, $\mathrm{HNO}_{3}$ is the most efficient for $\mathrm{Nb}$ stripping from the loaded solvent.

Table 10. Effect of stripping agent type upon $\mathrm{Ta}$ and $\mathrm{Nb}$ stripping efficiencies.

\begin{tabular}{ccc}
\hline Stripping agent & \multicolumn{2}{c}{ Stripping efficiency, \% } \\
\cline { 2 - 3 } & $\mathbf{T a}$ & $\mathbf{N b}$ \\
\hline $\mathrm{Dist}_{2} \mathrm{H}_{2} \mathrm{O}$ & 39.73 & nil \\
$0.3 \mathrm{M} \mathrm{H}_{2} \mathrm{SO}_{4}$ & 10.95 & 16.70 \\
$0.3 \mathrm{M} \mathrm{HF}$ & 5.32 & 29.90 \\
$0.3 \mathrm{M} \mathrm{HNO}_{3}$ & nil & 49.70 \\
\hline
\end{tabular}




\section{Tantalum stripping}

\section{i) Effect of stripping time}

The effect of stripping time upon Ta stripping efficiency was studied in the range from 3 to $9 \mathrm{~min}$ at the fixed conditions of $\mathrm{A} / \mathrm{O}$ ratio of 1:1 using dist. water as stripping medium. The corresponding Ta stripping efficiencies were measured using ICP-MS and tabulated in Table (11). From the obtained results, it was found that 9 min stripping time is sufficient to bring almost complete Ta content $(99.34 \%)$ in the strip solution while $\mathrm{Nb}$ remains in the organic phase.

Table 11. Effect of time upon Ta stripping efficiency.

\begin{tabular}{ccc}
\hline Time, $\boldsymbol{\text { min }}$ & \multicolumn{2}{c}{ Stripping efficiency, \% } \\
\cline { 2 - 3 } & $\mathbf{T a}$ & $\mathbf{N b}$ \\
\hline 3 & 39.73 & nil \\
5 & 68.90 & nil \\
7 & 81.32 & nil \\
9 & 99.34 & nil \\
\hline
\end{tabular}

\section{ii) Construction of McCabe-Thiele diagram for Ta stripping}

From the equilibrium stripping data and the corresponding McCabe-Thiele diagram shown in Fig. 3, the theoretical number of stripping stages would be determined after fitting of the operating line. These data have been obtained by contacting several loaded solvent aliquots with distilled water for 9 min using different $\mathrm{A} / \mathrm{O}$ ratios. Accordingly, three theoretically stripping stages would be required for almost complete Ta stripping.

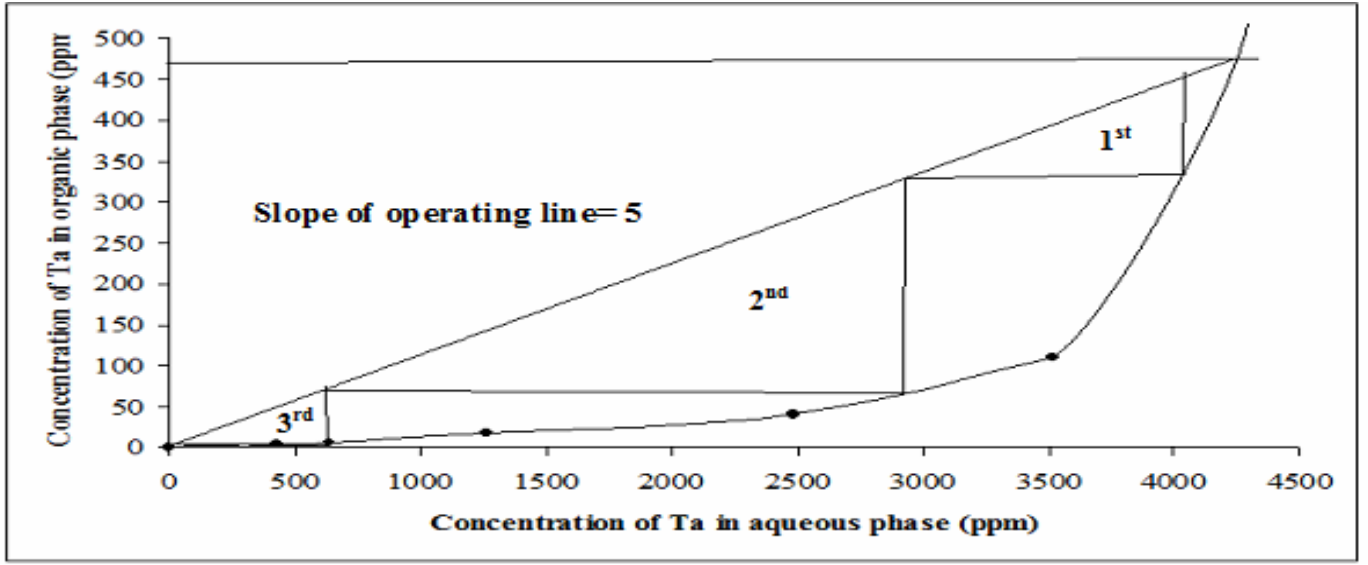

Fig. 3. McCabe-Thiele diagram for Ta stripping.

\section{Niobium stripping}

Referring to Table (10), $\mathrm{HNO}_{3}$ is the most efficient for $\mathrm{Nb}$ stripping from the loaded solvent free of Ta. 


\section{i) Effect of acid concentration}

The different concentrations of $\mathrm{HNO}_{3}$ were varied from 0.3 to $1.2 \mathrm{M}$ at the fixed conditions of $\mathrm{A} / \mathrm{O}$ ratio of $1 / 1$ and $12 \mathrm{~min}$ as contact time. The corresponding stripping efficiencies are measured and tabulated in Table (12). From the obtained data, it is concluded that the best nitric acid conc. for stripping of $\mathrm{Nb}$ is $1.2 \mathrm{M}$ to realize $99.55 \%$ stripping efficiency.

Table 12. Effect of $\mathrm{HNO}_{3}$ concentration upon $\mathrm{Nb}$ stripping efficiency.

$\mathrm{HNO}_{3}$ conc., $\mathrm{M}$.

0.3

0.6

0.9

1.2
Nb Stripping efficiency, \%

55.24

70.90

89.50

99.55

\section{ii) Effect of stripping time}

The effect of stripping time upon $\mathrm{Nb}$ stripping efficiency was studied in the range from 3 to $12 \mathrm{~min}$. at $1.2 \mathrm{M} \mathrm{HNO}_{3}$ and $\mathrm{O} / \mathrm{A}$ ratio $1 / 1$. From the obtained results (Table 13), it is found that 12 min as stripping time is sufficient to bring almost all $\mathrm{Nb}$ content into the stripping solution.

Table 13. Effect of time upon $\mathrm{Nb}$ stripping efficiency.

\begin{tabular}{cc}
\hline Time, $\boldsymbol{m i n}$ & Nb Stripping efficiency, $\%$ \\
\hline 3 & 63.50 \\
6 & 74.66 \\
9 & 87.30 \\
12 & 99.55 \\
\hline
\end{tabular}

\section{iii) Construction of McCabe-Thiele diagram for $\mathrm{Nb}$ stripping}

From the equilibrium stripping data and the corresponding McCabe-Thiele diagram as shown in Fig. 4, the theoretical number of stripping stages would be determined. These data have been obtained by contacting several loaded solvent aliquots with a mixture of $1.2 \mathrm{M} \mathrm{HNO}_{3}$ for 12 min using different $\mathrm{A} / \mathrm{O}$ ratios. From the McCabe- Thiele diagram, and according to the given operating line, theoretically four stripping stages are required for almost complete stripping of $\mathrm{Nb}$ from the loaded isodecanol. 


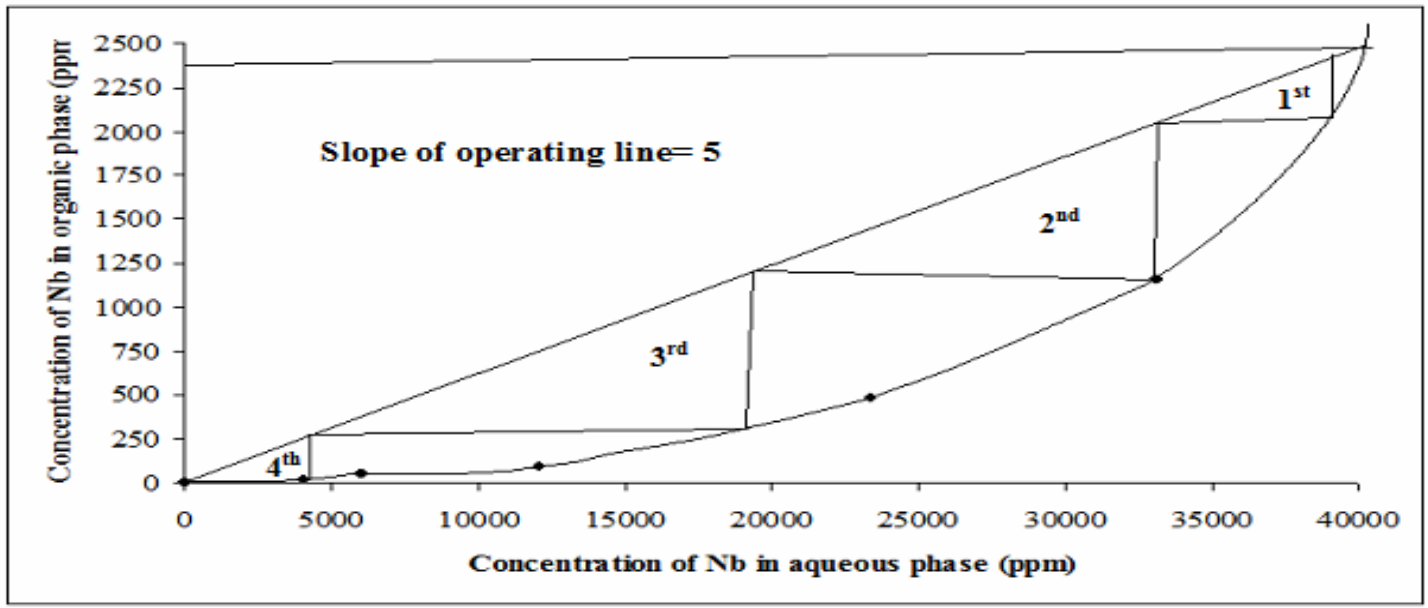

Fig. 4. McCabe-Thiele diagram for $\mathrm{Nb}$ stripping.

\section{Tantalum and niobium precipitation}

\section{i) Tantalum precipitation}

By neutralizing the corresponding Ta strip solution using ammonia solution, Ta was completely precipitated at $\mathrm{pH} 5.5$. After calcination, a relatively pure $\mathrm{Ta}_{2} \mathrm{O}_{5}$ was obtained and analyzed using ICP-MS which $96 \%$ purity.

\section{ii) Niobium precipitation}

By neutralizing the corresponding $\mathrm{Nb}$ strip solution using ammonia solution, $\mathrm{Nb}$ was completely precipitated at $\mathrm{pH} 7.5$. The product obtained was calcined and analyzed using ICP-MS to show $94 \%$ purity.

\section{Conclusion}

The acid agitation leaching procedure using $\mathrm{H}_{2} \mathrm{SO}_{4}$ was applied for leaching of $\mathrm{Nb}$, Ta and REEs metal values of the representative ore sample of Um Tomyem area, southwestern Sinai. The optimum conditions of acid agitation leaching step for almost complete dissolution of $\mathrm{Nb}$, Ta and REEs involved $300 \mathrm{~g} / \mathrm{l} \mathrm{H}_{2} \mathrm{SO}_{4}$ at $\mathrm{S} / \mathrm{L}$ ratio $1 / 2$ of $300^{\circ} \mathrm{C}$ for $3 \mathrm{~h}$. The obtained sulfate liquor is subjected to treatment via precipitation of REEs at $\mathrm{pH} 0.8$ using $10 \%$ oxalic acid before applying solvent extraction for $\mathrm{Nb}$ and $\mathrm{Ta}$. Subsequently, $\mathrm{Ta}$ and $\mathrm{Nb}$ recovered together by solvent extraction technique using isodecanol (100\%) at different contact times for different $\mathrm{pH}$ values and stripped by distilled water and different concentrations of acids. The studied optimum extraction conditions included $100 \%$ isodecanol conc., an O/A of $1 / 1$ at a $\mathrm{pH}$ 0.9 of the treated sulfate solution and a contact time of $12 \mathrm{~min}$ to realize the extraction efficiencies of $\mathrm{Ta} 99.7 \%$ and $\mathrm{Nb} 99.3 \%$. The studied optimum conditions for stripping of $\mathrm{Ta}$ are distilled water as stripping agent, $\mathrm{A} / \mathrm{O}$ ratio 1/1 and 9 min as stripping time while $\mathrm{Nb}$ remained in the organic phase. The studied optimum conditions for stripping of $\mathrm{Nb}$ are $1.2 \mathrm{M} \mathrm{HNO}_{3}$ as stripping agent, $\mathrm{A} / \mathrm{O}$ ratio $1 / 1$ and $12 \mathrm{~min}$ as stripping time. Highly pure products of Ta 
and $\mathrm{Nb}$ have been prepared and analyzed using ICP-MS. Finally, a technical flowsheet is proposed for separation of $\mathrm{Ta}$ and $\mathrm{Nb}$ from the treated sulfate leach liquor as shown in Fig. 5.

Sulfate Leach Liquor

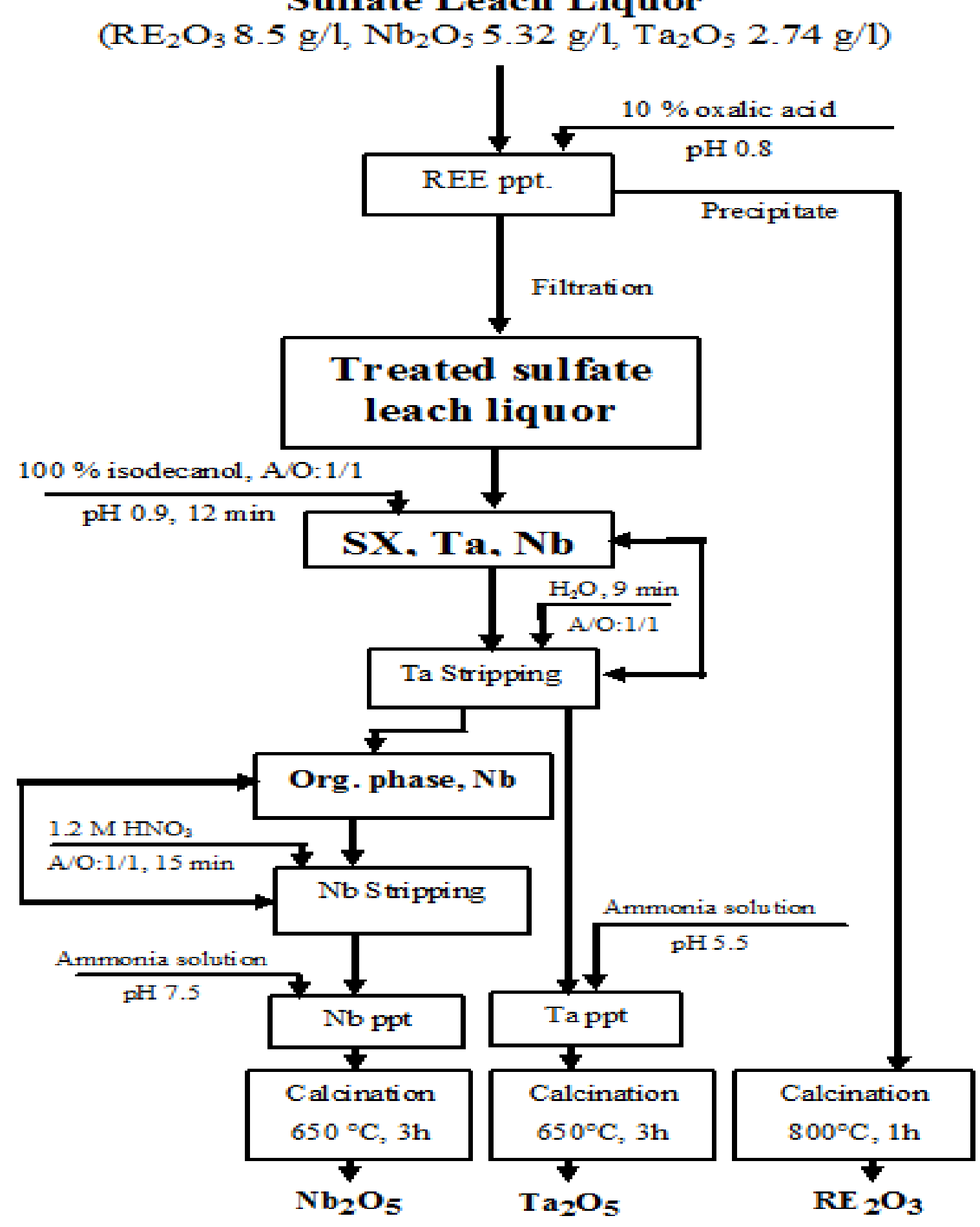

Fig. 5. Proposed technical flowsheet for the treated sulfate solution. 


\section{References}

Agulyansky, A.; Agulyansky, L. and Travkin, V.F. (2004): "Liquid-Liquid Extraction of Tantalum with 2-Octanol", Chemical Engineering and Processing Journal, 43 (10), 1231-1237.

Ayanda, O.S. and Adekola, F.A. (2011): "A Review of Niobium-Tantalum Separation in Hydrometallurgy", Journal of Minerals \& Materials Characterization \& Engineering, 10 (3), 245-256.

Borchers, P. and Korinek, G.J. (1981): "Extractive Metallurgy of Ta, in Extractive Metallurgy of Refractory Metals", Sohn, H.Y., Carlson, O.N., and Smith, J.T. (Eds.), Conf. Proc., the Met. Soc. of AIME, Warrendale, Pennsylvania, 95-106.

Campderros, M.E. and Marchese, J. (2001): "Transport of Niobium (V) Through a TBP-Alamine 336 Supported Liquid Membrane from Chloride Solutions", Hydrometallurgy, 61, 89-95.

Cunningham, L.D. (2000): "Columbium (Niobium) and Tantalum", USGS Minerals.

Eckert, J. (1995): "Hydrometallurgical Processing of $\mathrm{Ta} / \mathrm{Nb}$ Compounds", Present State of the Art. Proceedings of International Symposium on Tantalum and Niobium, Germany, Tantalum-Niobium International Study Center, Belgium, 51-64.

El-Hazek, M.N.; Amer, T.E.; Abu El-Azm, M.G.; Issa, R.M. and ElHady, S.M. (2012): "Liquid-Liquid Extraction of Tantalum and Niobium by Octanol from Sulfate Leach Liquor", Arabian Journal of Chemistry, 5, 31-39.

El-Hazek, M.N.; Amer, T.E.; Issa, R.M.; Abu El-Azm, M.G.; Omar, S.A. and El-Hady, S.M. (2009): "Characterization and Breakdown of South Gabal El A'urf Polymineralized Ore Material", Eurasian Chemicotechnological Journal, 11 (2).

El Hussaini, O.M. (2009): "Extraction of Niobium from Sulfate Leach Liquor of Egyptian Ore Sample by Triazoloquinazolinone", Trans. Nonferrous Met. Soc. China, 19, 474-478.

El Hussaini, O.M. and Mahdy, M.A. (2002): "Sulfuric Acid Leaching of Kab Amiri Niobium-Tantalum Bearing Minerals, Central Eastern Desert, Egypt”, Hydrometallurgy, 64 (3), 219-229.

El Hussaini, O.M. and Mahdy, M.A. (2001): "Extraction of Niobium and Tantalum from Nitrate and Sulfate Media by Using MIBK", Mineral Processing and Extractive Metallurgy Review, 22 (2), 633-650.

El Hussaini, O.M. and Mahdy, M.A. (1998): "Breaking Down of Ras Baroud Niobium Tantalum Ore by Sodium Hydroxide Fusion", J. Anal. Chem., Egypt, 7, 113-125. 
El Hussaini, O.M. and Rice, N.M. (2004): "Liquid - Liquid Extraction of Niobium and Tantalum from Aqueous Sulfate / Fluoride Solutions by A Tertiary Amine", Hydrometallurgy, 72, 259-267.

Gupta, C.K. and Suri, A.K. (1994): "Extractive Metallurgy of Niobium", CRC Press, Boca Raton, London, Tokyo.

Hayes, K. and Burge, R. (2003): "Coltan Mining in the Democratic Republic of Congo: How Tantalum using Industries can Commit to the Reconstruction of the DRC", Fauna \& Flora International, Cambridge, UK.

He; Cheng-yi; Liu; Zhi-ming; Zhang and Hao-jun (1998): “Treatment of Fluorine-Containing Waste Gas from Hydrometallurgy of Tantalum and Niobium Ore", Nonferrous Metals, 50 (4), 141- 142 (in Chinese).

Htwe, H.H. and Lwin, K.T. (2008): "Study on Extraction of Niobium Oxide from Columbite - Tantalite Concentrate", International Journal of Chemical, Molecular, Nuclear, Materials and Metallurgical Engineering, 2 (10), 223-225.

IAEA (2003): "Extent of Environmental Contamination by Naturally Occurring Radioactive Material (Norm) and Technological Options for Mitigation", Appendix IV [R], p. 164.

Irfan, M.S.K. and Ahmad, M.I. (2014): "Extraction of Niobium from Ore Deposits in KPK, Pakistan", NUST Journal of Engineering Sciences, 7 (1), 1-4.

Lowder, S. (2012): "Demand for Key Rare Earths, Niobium and Ferroalloys Soaring:Handwerge".http://www.mineweb.com/mineweb/view/mineweb /en/page72102?oid=145424\&sn=Detail 4

Maiorov, V.G.; Nikolaev, A.I.; Sklokin, L.I. and Baklanova, I.V. (2001): "Extractive Recovery of Tantalum (V) and Niobium(V) with Octanol from Hydroflouric Acid Solutions Containing Large Amounts of Titanium (IV)", Russian J. of Applied Chemistry, 74 (6), 945-949.

Mayorov, V.G. and Nikolaev, A.I. (2002): "Tantalum (v) and Niobium (v) Extraction by Octanol", Hydrometallurgy, 66, 77-83.

Merczenko, Z. and Balcerzak, M. (2000): "Separation, Preconcentration and Spectrophotometry in Inorganic Analysis", Elsevier, 341-350.

Moss, R.L.; Tzimas, E.; Kara, H.; Willis, P. and Kooroshy, J. (2011):

"Critical Metals in Strategic Energy Technologies: Assessing Rare

Metals as Supply-Chain Bottlenecks in Low-Carbon Energy

Technologies". http://setis.ec.europa.eu/newsroom-items

folder/copy of jrc-report-on critical metals-in-strategic-energy technologies.

Nete, M.; Purcell, W. and Nel, J.T. (2016): "Hydrometallurgical Separation of Niobium and Tantalum: A Fundamental Approach”, JOM, 68 (2). 
Pell, J. and Hora, Z.D. (1990): "High-Tech Metals in British Columbia", issued by Geological Survey Branch, Canada, 19.

Ritcey, G.M. and Ashbrook, A.W. (1979): "Solvent Extraction Principles and Applications to Process Metallurgy (Part II)", Chapter 4.11, Elsevier Publisher, p.362.

Shapiro; Leonard and Brannock, N.W. (1962): "Rapid Analysis of Silicate, Carbonate and Phosphate Rocks", U.S. Geol. Surv. Bull. 1144A, A1 A65.

Wang, X.; Zheng, S.; Xu, H. and Zhang, Y. (2009): "Leaching of Niobium and Tantalum from a Low-Grade Ore using a KOH Roast-Water Leach System", Hydrometallurgy, 98, 219-223.

Zhou, H.; Zheng, S. and Zhang, Y. (2005): "Leaching of a Low Grade Niobium-Tantalum Ore by Highly Concentrated Caustic Potash Solution", Hydrometallurgy, 80 (1-2), 83-89.

Zhu, Z. and Cheng, C.Y. (2011): "Solvent Extraction Technology for the Separation and Purification of Niobium and Tantalum: A Review", Hydrometallurgy, 107 (1-2), 1-12. 
فصل التتتالوم والنيوبيوم من محلول الكبريتات المعالج مستخدما أيزوديكانول صالح محمد الهادى حسن

هيئة المواد النووية : ص.ب 530 المعادى - القاهرة ـ مصر

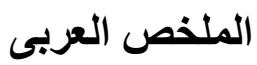

تتاول البحث معالجة عينة تكنولوجية من الصخور الرسوبية متعددة العناصر مجمعة من جنوب غرب سيناء - و التى تحتوى على 2,61 \% أكاسيد الأرضيات النادرة (RE2)

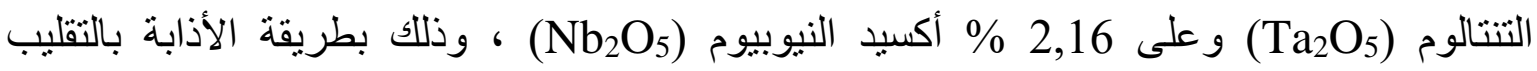

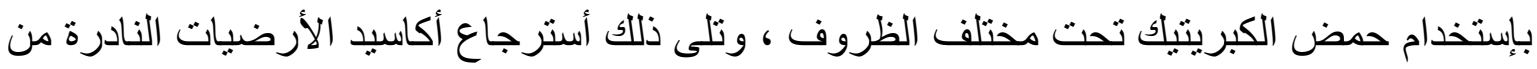
محلول الأذابة فى صورة الأوكسالات ، بينما تم دراسة أستخلاص النيوبيوم والتنتالوم من المحلول المتخلف بمذيب عضوى أيزوديكانول ، وبعد التوصل إلى تحديد الظروف المثلى لكلا من عملتى " الأستخلاص و الأسترجاع " للنيو بيوم و التنتالوم. تم تحضير ركاز وبدو عالى النقاوة لكلا من منتج النيوبيوم و التنتالوم وتم تحليلها بإنتخدام مطياف البلازما (ICP-MS). 